\title{
PROJETOS DE EXTENSÃO: UM DIFERENCIAL PARA O PROCESSO DE FORMAÇÃO
}

Rodrigo Rodrigues Menegon, Sérgio Augusto Gouveia Júnior, Marcia Regina Canhoto Lima, José Milton Lima

Universidade Estadual Paulista - UNESP - Presidente Prudente - SP.

\section{RESUMO}

Este ensaio tem como escopo mostrar aos leitores a importância da Extensão Universitária por meio de projetos de extensão voltados à área da educação física escolar da UNESP de Presidente Prudente, explanar a relevância que a extensão universitária tem no processo de formação dos indivíduos participantes e relatar os pontos de maior destaque para que este processo se torne um verdadeiro diferencial na vida do acadêmico, para que ele, consequentemente, obtenha sucesso e satisfação na atividade profissional escolhida. Os procedimentos adotados foram subsidiados por métodos da pesquisa qualitativa; utilizou-se um questionário aplicado aos alunos do curso de educação física que participaram de projetos de extensão. Os resultados apontaram que atividades dessa natureza, no processo de formação inicial, são significativas para a construção de conhecimentos que irão fundamentar a prática profissional.

Palavras-chave: Projetos de Extensão, Educação Física Escolar, Processo de Formação.

\section{INTRODUÇÃO E OBJETIVO}

O termo universidade deriva de Universo; e isso evidencia que uma instituição de ensino, para ser devidamente chamada de universidade, deve explorar todas as áreas do conhecimento científico por meio de multidisciplinaridade e interdisciplinaridade.

Explorando os conhecimentos científicos que produz, a universidade vem atuar em três frentes distintas. Uma delas é o ensino, que permite a formação profissional, técnica e científica às pessoas. Outra é a pesquisa, que é base para a busca e descoberta do conhecimento científico. É através da pesquisa realizada pela universidade que a ciência se desenvolve em busca do conhecimento da realidade. Finalmente, inserida neste contexto, mas não necessariamente em último lugar, está a extensão universitária, que oferece a diversidade conceitual e a prática que intervém significativamente no "pensar" e no "fazer" no interior da universidade (OLIVEIRA, 2001).

Esses três eixos apresentam-se, no âmbito das universidades brasileiras, como uma de suas maiores virtudes. São a expressão de compromisso educacional e social que essas instituições possuem. O exercício dessas dimensões é requerido como dado de excelência no ensino superior, essencialmente voltado para a formação profissional que é a luz da apropriação e produção do conhecimento científico. 
Pensando neste sentido, podemos dizer que a extensão universitária é um processo educativo e científico. Ao promovê-la, estamos (re)produzindo um conhecimento de suma importância: um conhecimento que viabiliza a relação transformadora entre a Universidade e a Sociedade e vice-versa. Uma extensão que é experiência na sociedade, uma práxis de um conhecimento acadêmico que não se basta em si mesmo, que estará alicerçado numa troca de saberes executada entre representantes sociais que produzem os saberes populares e pesquisadores acadêmicos que têm como objetivo produzir e aplicar ciência. Muitas vezes há, nessas práticas, confronto. E dele é que podem surgir novos saberes - produzidos exatamente pelo diálogo (ainda que tenso) entre a comunidade científica e a população que se beneficia dos projetos de extensão e os alimenta. (PLANO NACIONAL DE EXTENSÃO UNIVERSITÁRIA, 2000/2001).

A Extensão universitária passa a ser integrante na dinâmica pedagógica do processo de formação acadêmica, expandindo a produção de conhecimento. Uma nova visão que permite o diálogo entre professores e alunos, oportunizando uma flexibilidade no currículo, e possibilitando ao aluno a obtenção de uma formação mais crítica e construtiva (JEZINE, 2004).

A Extensão Universitária vivencia um momento extremamente importante para sua consolidação como fazer acadêmico; ela permite que a Universidade vá até a comunidade, ou a receba em seus "campi", disseminando o conhecimento de que é detentora. Verifica-se que ela é uma forma de a universidade socializar e democratizar o conhecimento, levando-o aos não universitários (SILVA, 1996).

Uma das classificações da extensão universitária é o projeto de extensão - uma ação processual e contínua de caráter educativo, social, cultural, científico ou tecnológico, com objetivo específico e prazo determinado, podendo ou não, estar vinculado a um programa.

Os projetos de extensão que desenvolvemos em nosso trabalho estão voltados à área da educação física escolar; alicerçam-se na Lei de Diretrizes e Bases da Educação Nacional, buscam garantir a educação física como um componente curricular obrigatório, e trazem, dentre seus objetivos mais explícitos, a possibilidade de proporcionar aos alunos da rede municipal de ensino de Presidente Prudente aulas de educação física com professores com conhecimento específico, uma vez que estes não têm acesso direto a professores especializados.

Assim, as atividades desenvolvidas nos projetos buscam oferecer a esses estudantes uma gama de atividades que contemplem o desenvolvimento harmônico dos aspectos físicos, 
cognitivos, afetivos e sociais. Já para os licenciandos do curso de educação física, elas promovem, em conjunto, a vivência e a experiência docente responsável e comprometida.

\section{METODOLOGIA}

O caminho norteador para esta pesquisa é o estudo qualitativo de cunho descritivo. Minayo,(2001) aponta que a pesquisa qualitativa busca trabalhar com o universo de significados, motivos, aspirações, crenças, valores e atitudes, o que corresponde a um espaço intenso das relações, dos processos e dos fenômenos. Escolhemos fazê-la com caráter descritivo que, segundo Lakatos, (1990) pode ser delineado por quatro procedimentos,: descrição, registro, análise e interpretação de fenômenos atuais.

A pesquisa contou com 12 participantes, todos eles atuais universitários e ex- universitários do curso de educação física da FCT/UNESP de Presidente Prudente que eram bolsistas ou voluntários de projetos de extensão, voltados à área de educação física escolar.

Para diagnosticar as contribuições que os projetos de extensão proporcionam aos seus participantes durante o processo de formação, realizou-se a aplicação de um questionário aberto, o qual possuía o seguinte questionamento: Mediante a sua participação em projetos de extensão, voltados à área de Educação Física Escolar, durante sua vida universitária, descreva quais as observações e contribuições mais relevantes que esta participação teve para seu processo de formação.

Segundo Minayo (2001), uma das fases da pesquisa que executamos é a análise de dados qualitativos. E ela reúne três finalidades: estabelecer uma compreensão dos dados coletados, confirmando ou não os pressupostos da pesquisa ou responder as questões formuladas e ampliar o conhecimento sobre o assunto pesquisado articulando-o ao contexto cultural do qual se faz parte. Relacionando e interpretando, assim, as respostas dos participantes por meio de temas que se encaixavam de acordo com suas colocações. E foi dessa fase que retiramos os resultados os quais descrevemos em seguida.

\section{RESULTADOS}

Os resultados encontrados apontam uma relevante contribuição por parte dos projetos de extensão no processo de formação acadêmica. Para que as observações e contribuições fossem relatadas de forma detalhada, as respostas foram divididas em três eixos temáticos, sendo eles: 
relação entre a teoria-prática, conhecimento da realidade do âmbito escolar no qual se está inserido, e o retorno às produções de conhecimento científico.

O ponto de maior relevância encontrado nas respostas foi a da importância de conciliar a relação entre teoria/prática, mais conhecida como práxis pedagógica. Esta relação entre teoria/prática possibilita ao aluno tornar sua atividade profissional diferenciada em relação aos demais profissionais da área, além de fazer a diferença no seu processo de formação e futuro campo de atuação.

Outro aspecto levantado pelos participantes foi à importância de se conhecerem as realidades presentes no âmbito escolar, que os projetos de educação física escolar proporcionam, pois eles permitem que o conhecimento e a vivência desta realidade junto do ambiente escolar, possibilitam a execução e reelaboração de métodos de trabalho estimulam a criação de estratégias e recursos que possibilitam uma relação professor aluno agradável, capaz de contribuir para o desenvolvimento integral e pleno dos agentes do processo educativo de acordo com o contexto apresentado por meio das várias culturas no qual estão inseridos.

A produção de conhecimento foi outro ponto destacado pelos participantes, pelo fato de os projetos proporcionarem um retorno às pesquisas e aos estudos sobre os mais diferentes grupos sociais e segmentos da sociedade.

Assim, a extensão universitária torna-se importante fonte de informações para o mundo acadêmico, possibilitando o desenvolvimento e as publicações de experiências extensionistas e pesquisas, as quais constituem importante ferramenta de divulgação de suas produções resultantes de projetos e de atividades de extensão universitária.

\section{DISCUSSÃO}

De acordo com os resultados apresentados na pesquisa, salientamos que, ao falarmos em práxis, falamos na atividade docente, porque a prática do professor é que a aprendizagem ocorra em conseqüência da atividade de ensinar (PIMENTA, 2006, p. 83). Fundamentada em Marx, Pimenta (2006, p.86) traz como conceito de práxis: a "atitude (teórico-prática) humana de transformação da natureza e da sociedade. Não basta conhecer e interpretar o mundo (teórico) é preciso transformá-lo (práxis)".

A integração entre teoria e prática é uma linha essencial no processo de formação, pois possibilita orientar o conhecimento para a construção de um saber. Essa construção do saber deve ser consciente por parte do acadêmico, para que, desse modo, a qualidade no fazer pedagógico no 
âmbito escolar se efetive e, assim, diminua a insegurança do acadêmico, quando este vai para a prática (BRAUNER, 1999, p.324).

Já no aspecto relatado sobre a importância de conhecer a realidade do âmbito escolar na qual se está inserido, Gadotti (1999) complementa que o educador - para pôr em prática o diálogo - não deve colocar-se na posição de detentor do saber, e sim, colocar-se na posição de quem não sabe tudo, estando sempre disposto a evoluir, expandir e aprimorar o conhecimento, reconhecendo, ainda, que mesmo um analfabeto é portador do conhecimento mais importante: o da vida.

Quanto à relevância de produzir conhecimento, o aluno - enquanto pesquisador -vai alimentar-se de diversas fontes para enriquecer o seu arcabouço teórico, não se permitindo ser um mero reprodutor de conteúdos de livros ou de fragmentos retirados aleatoriamente da Internet ou de obras de outrem (DEMO, 1997).

E com isso ele vai adquirir a competência da pesquisa saindo da condição de objeto e tornando-se sujeito parceiro que atuará junto do orientador, reconstruindo o seu conhecimento, de forma ativa e participativa. Para tanto, o aluno precisa ser desafiado a pesquisar, sendo motivado a elaborar suas conclusões, começando, assim, a reconstrução do seu conhecimento.

Fundamentando-nos nas observações relatadas, podemos destacar que os projetos de extensão voltados às áreas da educação física escolar, apresentam grandes contribuições para a comunidade escolar e universitária, tornando-se imprescindíveis para o processo de formação de seus participantes.

A Extensão Universitária conta com condições formadoras diferenciadas que enriquecem os conhecimentos de alunos e docentes, levando-os a mais alta qualificação na área de atuação e, muitas vezes, ao encontro do mais importante significado de seu trabalho e de sua carreira (ZUANON, 2010). Além disso, ela contribui significativamente com o ensino e o desenvolvimento de pesquisas, pois trabalha com problemas impostos pela vida, o que conduz à realização de intervenções intra e/ou extramuros da Universidade, na busca de soluções efetivas para problemas sociais.

\section{CONCLUSÃO}

Até o presente momento e pelos documentos consultados até agora, parece inegável a oportunidade que a Extensão Universitária tende a oferecer aos alunos universitários: colocar em prática os conhecimentos adquiridos em sala de aula e, a partir dessa experiência, repensar e 
reelaborar cada um daqueles que, no exercício prático, distanciou-se da realidade planejada e/ou descrita em momentos de atividade teórica. Em outras palavras, isso significa práxis: a teoria (estudo) que se origina da prática e a prática que se origina da teoria. A possibilidade de ensinoaplicação é uma maneira bem planejada de preparar seus profissionais não apenas com a leitura e discussão de textos no ambiente universitário, mas também com a elaboração e a execução de estratégias do ensino-aplicação, as quais esclarecem que o verdadeiro conhecimento só é adquirido com a execução desses dois elementos (SILVA, 1996).

Por tudo que foi observado e verificado, pode-se, então relatar que a extensão universitária, em particular os projetos de extensão em educação física escolar da UNESP, são de suma importância para os seus alunos participantes, pois estes vêm complementar, muitas vezes, o currículo fragmentado do curso. Além de fazer uma integração do aluno com a realidade da atividade profissional escolhida, possibilita ainda, demonstrar em que situação se encontra seu campo de trabalho, e, com isso, evidenciar as perspectivas que o aluno terá naquele momento.

Portanto, estes projetos oportunizam aos alunos o contato com o mercado, a sociedade e a comunidade em que estão inseridos. E isso oportuniza vivências, experiências e realidades bem diferentes daquelas as quais são desenhadas dentro das quatro paredes encontradas na sala de aula. Conseqüentemente, com esse diferencial em sua formação - o licenciando desenvolve melhor o seu senso-crítico e expande seus horizontes em busca da elaboração e apropriação do conhecimento significativo.

\section{REFERÊNCIAS}

BRASIL. Lei no 9.394/96 - Lei de diretrizes e bases da educação Nacional. Brasília: Ministério da Educação e Cultura, 1996.

BRAUNER, Vera Lúcia Pereira. La formación del profesorado de educación física en la UFGRS, Porto Alegre (Brasil): tendencias teóricas. Tese de doctorado: Departamento de Teoría I Historia de l’Educación División de Ciencias de l’Educación Universidad de Barcelona, 1999.

CORRÊA, E. J. (Org.). Extensão universitária: organização e sistematização. Belo Horizonte: Coopmed, 2007. Disponível em: http://www.renex.org.br/documentos/Colecao-ExtensaoUniversitaria/06-Organizacao-e-Sistematizacao/Organizacao-e-Sistematizacao.pdf. Acesso em: 1 de dezembro de 2011.

DEMO, Pedro. Educar pela Pesquisa. Campinas, SP: Autores Associados, 1997.

Fórum de Pró-Reitores de Extensão das Universidades Públicas Brasileiras. Plano Nacional de Extensão Universitária - Edição Atualizada. Fórum de Pró-Reitores de Extensão das Universidades Públicas Brasileiras e SESu / MEC, Brasília. 2000 / 2001. 
GADOTTI, M. História das idéias pedagógicas. 8. ed. São Paulo: Ática, 1999.

JEZINE, Edineide. As Práticas Curriculares e a Extensão Universitária. In: CONGRESSO BRASILEIRO DE EXTENSÃO UNIVERSITÁRIA, 2. Anais do... Belo Horizonte. Disponível em:

<http://www.ufmg.br/congrext/Gestao/Gestao12.pdf> Acesso em: 20 de agosto de 2011. (2004)

LAKATOS, E. M. Fundamentos de metodologia cientifica. São Paulo: Atlas, 1990.

MINAYO, Maria Cecília de Souza. O desafio do conhecimento científico: pesquisa qualitativa em saúde. 2a edição. São Paulo/Rio de Janeiro: Hucitec-Abrasco, 1993

MINAYO, Maria Cecília de Souza (Org.). Pesquisa Social: teoria, método e criatividade.19.ed. Petrópolis: Vozes, 2001.

OLIVEIRA, José Arimatés de. A Universidade e a formação para a qualidade de vida. Da Vici. Textos Acadêmicos. Natal : UFRN/Diário de Natal, 28 de abril de 2001.

PIMENTA, Selma Garrido. Estágio na formação de professores: unidade teoria e prática. 7. ed. São Paulo: Cortez, 2006.

SILVA, Oberdan Dias da. O que é extensão universitária? <Disponível em http://www.ecientificocultural.com/ECC2/artigos/oberdan9.html > acesso em 29 nov, 2011 (1996)

ZUANON, A. C. C. Carta ao Leitor. Rev. Ciênc. Ext. v.6, n. 1, p.1, 2010. 